\title{
COPIM
}

\section{Combinatorial Books - Gathering Flowers - Part II}

Janneke Adema, Gary Hall, Gabriela Méndez Cota

Published on: Apr 29, 2021

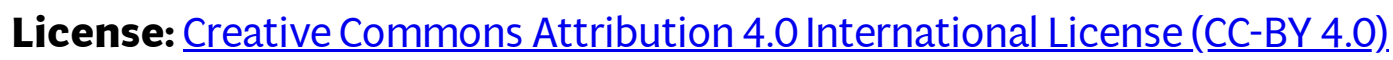


This is the second in a series of blog posts (part I is here and part III is to follow), which introduce one of the Pilot Projects we are conducting as part of the Experimental Publishing working group of the COPIM project. In these Pilot Projects, COPIM project members are collaborating with authors and publishers to create three or more experimental books. (For a typology of experimental books, see our previously published research report here). They are also documenting the publishing process along the way-through reflective blog posts such as this, for example. One of COPIM's Pilot Projects is run by Open Humanities Press (OHP) in collaboration with a group of scholars, technologists, and students from the Universidad Iberoamericana Ciudad de México (including Etelvina Bernal, Sandra Hernández Reyes, Sandra Loyola Guízar, Fernanda Rodríguez González, Yareni Monteón López, Deni Garciamoreno, $\underline{\text { Nidia Rosales, Xóchitl Arteaga Villamil and Carolina Cuevas), led by Dr Gabriela }}$ Méndez Cota. The Pilot, titled Combinatorial Books: Gathering Flowers, explores and encourages the revisiting and rewriting of books within the OHP catalogue as a means of generating radical new responses to them.

\section{Combinatorial Books}

For this Pilot Project, our aim is to create a research and publishing workflow that enables the creation of new combinatorial books out of existing open access books (or collections of books) that are available for reuse. Combinatorial creativity, which is the process of combining existing ideas to produce something new, can be perceived as a critique of the idea of the original genius - or, in the context of academia, of the single liberal humanist author (ㅇpova, 2011). We can find forms of combinatorial creativity in contemporary remix and cut-up cultures and practices. However, the cutting and pasting of texts to create new manuscripts as a form of 'remixing' can be traced all the way back to the practice of compiling scrapbooks or so-called commonplace books in Early Modern times. Commonplacing, as a method or approach to reading and writing, involved the gathering and repurposing of meaningful quotes, passages or other clippings from published books by copying or pasting them into a blank book. Often this meant writing out quotations by hand. But it could also involve the actual cutting and pasting of materials-especially with the proliferation of printed matter in the 18th century-and the inclusion of all kinds of annotations from drawings to graphs and

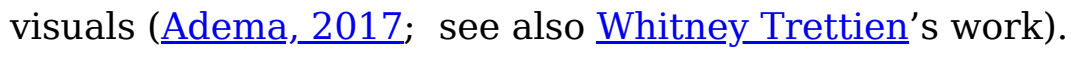




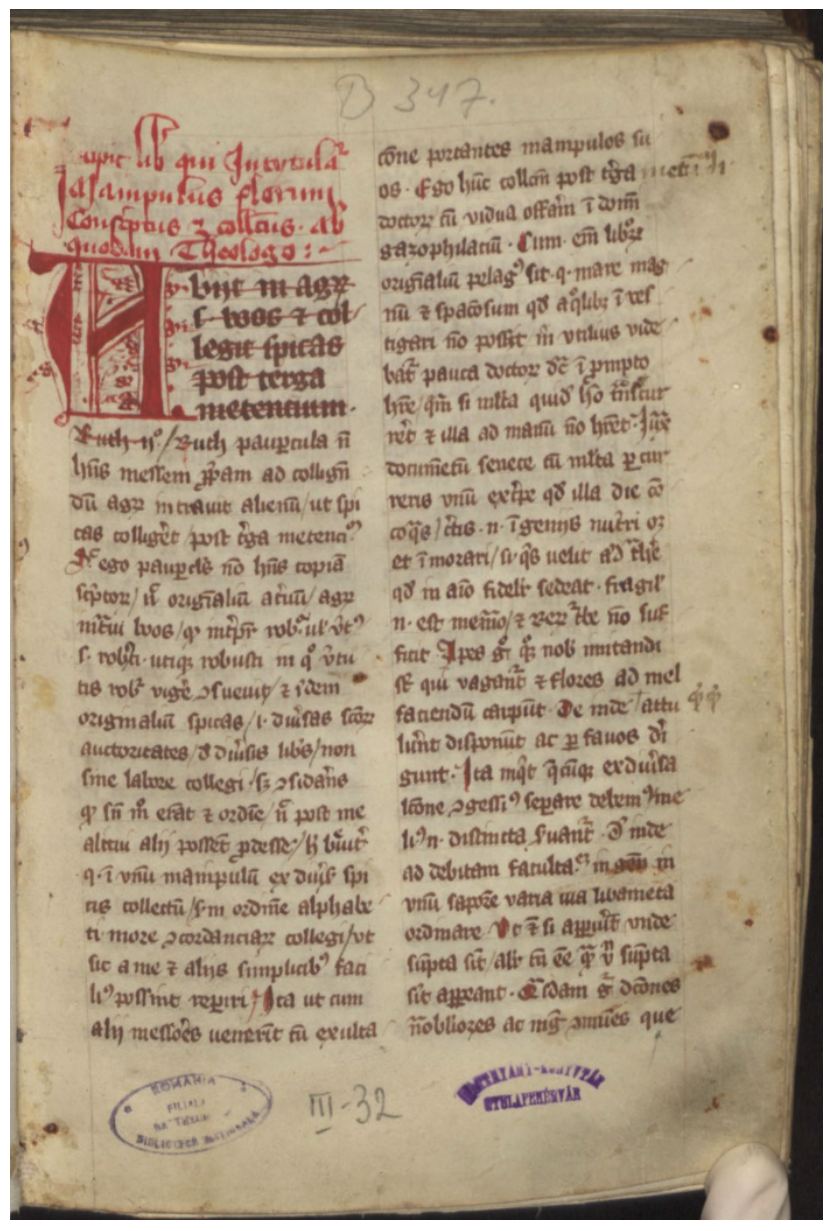

THOMAS OF IRELAND, MANIPULUS FLORUM
The florilegium (plural florilegia) is an earlier medieval version of the commonplace book. Both 'anthology' and 'florilegium' translate to 'gathering of flowers'-from the Latin flos (flower) and legere (to gather). Although the florilegium is literally a collection of illustrations of plants, the term was also used to denote a compilation of excerpts from other writings; or, according to Wikipedia, ' $\underline{\mathrm{a}}$ collection of fine extracts from the body of a larger work'.

Michael Marder and Anaïs Tondeur's The Chernobyl Herbarium, is a collection of 'fragments of reflections, meditations, recollections, and images - one for each year that has passed since the explosion of the Chernobyl nuclear power station in April 1986' (Marder and Tondeur, 2016). The book can be understood in the tradition of the florilegium, as a media form and

writing practice. But as the title indicates, Marder and Tondeur's book also reflects on the herbarium (a collection of preserved plants); or, in this context, the collection of photograms created by Tondeur from the imprints and impressions of radioactive plants, grown in the soil of the Chernobyl 'exclusion zone.' The Chernobyl Herbarium states that 'to select, arrange, and display is to create a herbarium.' In this sense, the book itself has become a living florilegium. Living, because the collection of photograms on which the book is based is still being updated on a yearly basis; but also because the book is spreading like a plant or weed, having been translated into several languages, including French, Basque, Spanish, Danish, and Portuguesetranslation being one of the most familiar forms of reuse within academia. 

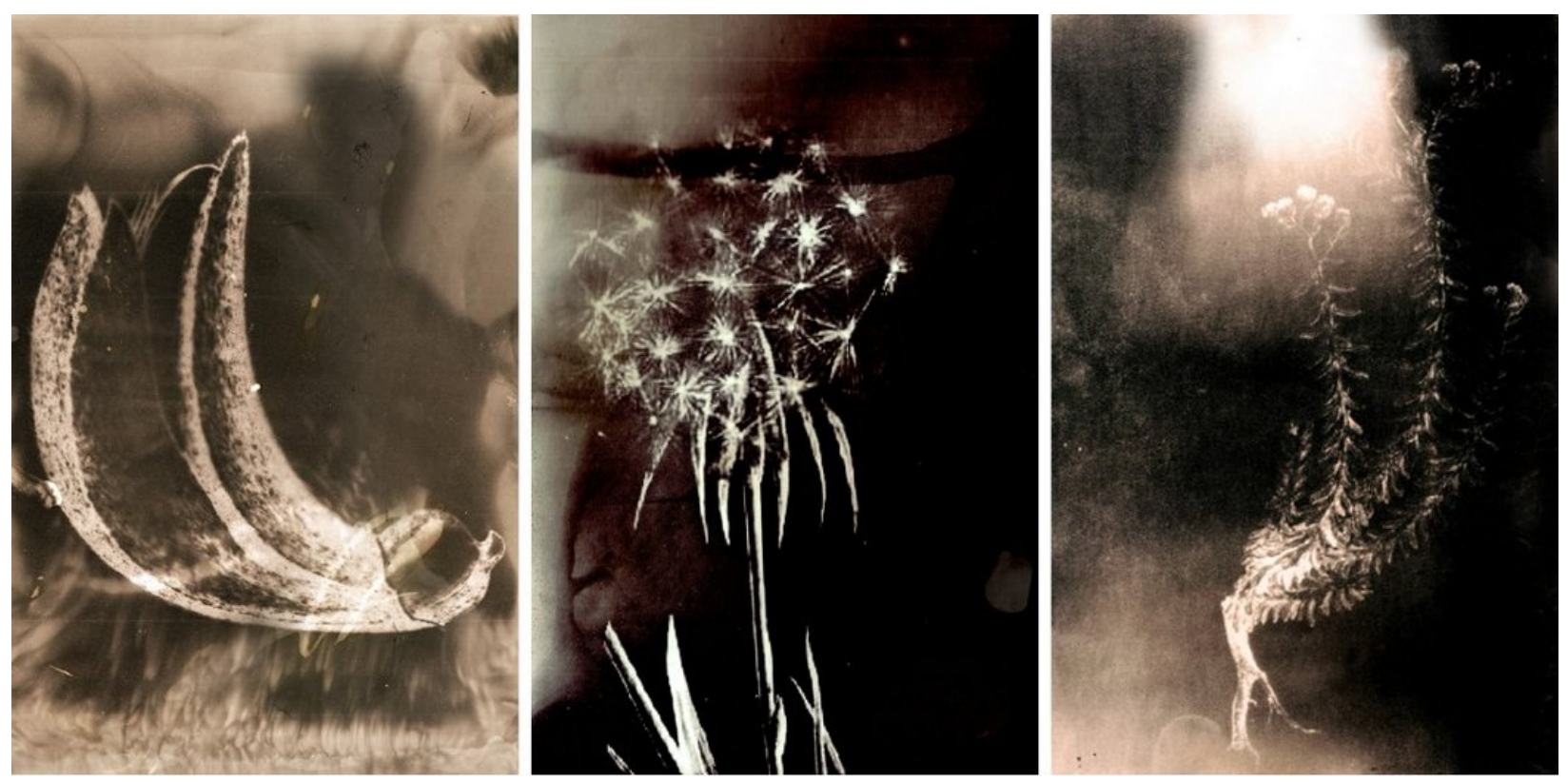

A selection of photograms from The Chernobyl Herbarium

The practice embodied in the florilegium, of gathering fragments and flowers, doesn't just relate to The Chernobyl Herbarium. It resonates with the work of Méndez Cotathe coordinator of the group of authors and technologists in Mexico who are engaging with Marder and Tondeur's book as part of this Pilot Project. Especially worth mentioning here is her research on plants, biotechnology, and biodiversity on which she published two books: Disrupting Maize: Food, Biotechnology and Nationalism in Contemporary Mexico (2016) examines the disruption and contamination of maize, while En Busca Del Quelite Perdido (In search of the lost quelite): recetario viviente para Cholula (FONCA, 2015) is at once a living photographic archive and a recipe book about the Mexican city of Cholula and quelite, the edible weeds that grow at the feet of maize plants there. Beyond specific projects, the idea of florilegium also relates to Open Humanities Press' (which is leading this Pilot Project) interest in the posthuman and the posthumanities, and as part of this, the agency of plants and living material. This area of work, for example, has also inspired Open Humanities Press' Liquid and Living Books series. 


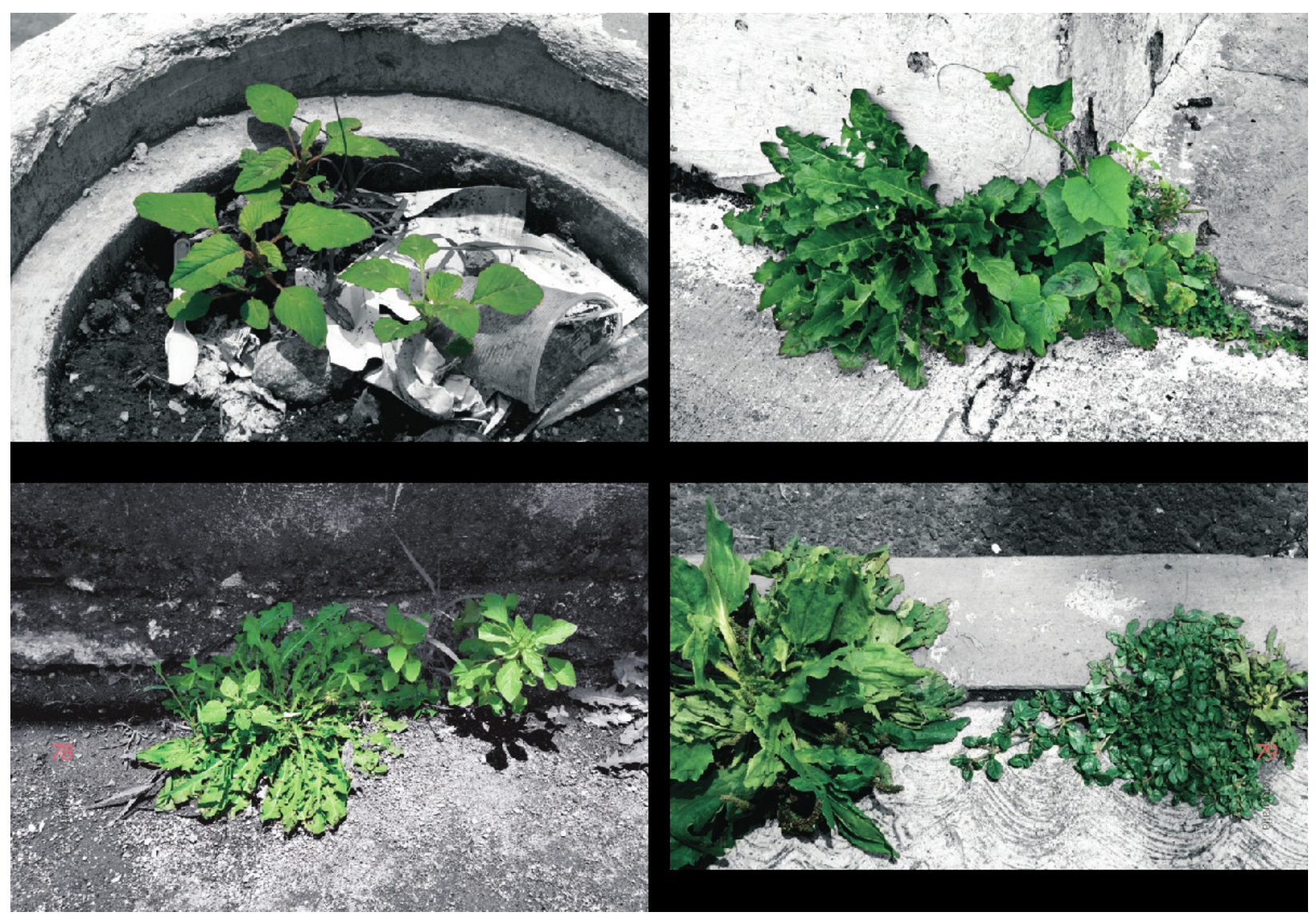

Quelites in Cholula. Photo: Angela Arziniaga González from En Busca Del Quelite Perdido

\section{The Pilot Project}

Combinatorial Books: Gathering Flowers addresses theoretical and practical concerns about contemporary academic publishing practices and the configuration of long-form texts by means of a series of collaborative writing experiments. From a publishing perspective, the experiment resonates with the question of how we can promote the uptake and reuse of open access book content. It poses the question, of how we can move from reuse and annotation to the creation of new combinatorial books? By grappling with these questions, the experiment promotes forms of collaborative editing and writing in an academic publishing landscape that is still dominated by singleauthored, closed access books. In this context, it can be seen as an exploration of writing that has as its starting point the position that every book is a community of other texts, readers, and authors (and thus materials, technologies and bodies). Texts draw on each other, in a dense network of implicit references. (Hence Roland Barthes' famous description of the text as a 'tissue of quotations'.) Citations offer a way to make some of these connections visible within the constraints of conventional copy right and 
authorship regimes. Open access publications made available under open licences remove (most) legal barriers to the more radical reuse of existing texts, enabling, for example, collage texts entirely composed of text snippets, or a remix in which several existing texts are woven together in the fashion of a parallel montage. Combinatorial Books will experiment with such possibilities in theory and practice, and thus promote the reuse of OA books as part of a workflow that enables the creation of new publications out of existing ones.

In principle we envision this Pilot Project as being able to work on several scales: it can have scholars engage with a single text, commenting on it, annotating it, revising it, rewriting it, remixing it, whilst we direct them to the available tools they can use to do so in a collaborative manner; or the project can employ a more elaborate set-up that involves several texts, even the catalogues of several presses, along with a fully established workflow and publishing environment to enable the creation of new combinatorial books.

For this first book in our Pilot Project, Combinatorial Books: Gathering Flowers, which is being created by Méndez Cota and her fellow re-writers, we are working with a relatively straightforward re-use, research, and publishing workflow based on (open) annotation, in combination with collaborative writing. The re-writers have begun to collaboratively annotate The Chernobyl Herbarium online PDF with the aid of the hypothes.is plugin, while categorising or ordering their annotations with the aid of custom tags. (Méndez Cota describes this process in more detail in the next blog post). At the moment we are devising a technical workflow that will enable us to export these annotations, grouped per tag, into a collaborative environment where the writing process can be captured and showcased as a way of exploring what it means to rewrite or produce research in a (semi-)open setting. Together with OHP we will then explore how this book can best be presented (in which forms and formats), reviewed, and archived. More about this new book and how it will 're-compose' The Chernobyl Herbarium through disappropriation as much as appropriation, will follow in the next blog post. 